\title{
Percepção pública sobre a produção e comercialização de laranjeiras doces
}

\section{geneticamente modificadas}

\author{
Public perception of the production and commercialization of genetically modified sweet orange
}

trees

Percepción pública de la producción y comercialización de naranjos dulces modificados genéticamente

\section{Resumo}

No decorrer das últimas décadas, a produção de alimentos transgênicos tem gerado debates em torno dos avanços das biotecnologias na agricultura e seus impactos sociais, políticos, econômicos e ambientais em todo o mundo, e principalmente no Brasil, país de notório destaque para o agronegócio. Como parte deste debate, o presente trabalho teve como objetivo compreender, através da aplicação de questionários on-line aos 318 entrevistados, a aceitação ou rejeição dos consumidores quanto ao potencial uso de frutos de laranjeiras doces geneticamente modificadas para o consumo humano e as perspectivas para a futura liberação da produção a nível comercial. Observou-se que há alta aceitação do consumo de laranjas transgênicas, porém estes produtos terão resistência por parte da população e de mercados importadores para uma possível produção e comercialização. Entretanto, observou-se que há alta perspectiva da população para que a transgenia se torne uma importante alternativa no controle das principais doenças dos citros que afetam drasticamente a produtividade deste setor.

Palavras-chave: Biotecnologia; Pesquisas; Resistência a doenças; Questionário.

\begin{abstract}
Over the past few decades, the production of transgenic food has generated debates around advances in agricultural biotechnology and their social, political, economic, and environmental concerns in the world, and especially in Brazil, a country with a notable prominence for agribusiness. As part of this debate, this study aimed to understand, through the application of online questionnaires to the 318 respondents, the acceptance or rejection of consumers regarding the potential use of genetically modified sweet orange fruit for human consumption and the perspectives for the future release of production at the commercial level. It was observed that there is high acceptance of the consumption of transgenic oranges, but these products will have resistance from part of the population and import markets for possible production and commercialization. However, it was observed that there is a high perspective of the population for transgenics to become an important alternative in the control of the main citrus diseases that drastically affect the productivity of this sector.
\end{abstract}

Keywords: Biotechnology; Research; Disease resistance; Questionnaire.

\section{Resumen}

En las últimas décadas, la producción de alimentos transgénicos ha generado debates en torno a los avances de la biotecnología en la agricultura y sus impactos sociales, políticos, económicos y ambientales en todo el mundo, y especialmente en Brasil, un país de notorio protagonismo para la agroindustria. Como parte de este debate, este estudio tuvo como objetivo comprender, a través de la aplicación de cuestionarios en línea a los 318 encuestados, la aceptación o rechazo de los consumidores con respecto al uso potencial de la naranja dulce modificada genéticamente para el consumo humano y las perspectivas para el futuro lanzamiento de producción a nivel comercial. Se observó que existe una alta aceptación del consumo de naranjas transgénicas, pero estos productos tendrán resistencia por 
parte de la población y los mercados de importación para una posible producción y comercialización. Sin embargo, se observó que existe una alta perspectiva de la población para que los transgénicos se conviertan en una alternativa importante en el control de las principales enfermedades de los cítricos que afectan drásticamente la productividad de este sector.

Palabras clave: Biotecnología; Investigación; Resistencia a enfermedades; Cuestionario.

\section{Introdução}

O advento de novas biotecnologias e a aplicação destas na agricultura impactou a produção agrícola mundial no decorrer das últimas décadas, especialmente, com a introdução das plantas geneticamente modificadas (Cohen, 1993). A transformação genética de plantas constitui na introdução controlada de um gene ou fragmento de DNA no genoma de uma planta (Diouf, 2003). Uma vez identificado, um gene responsável por uma determinada característica pode ser isolado, clonado e empregado em programas de melhoramento, através da transformação genética. Desta forma, características agronômicas importantes como resistência a doenças, pragas, herbicidas e tolerância a estresses abióticos podem ser introduzidas em plantas cultivadas através dessa técnica (Brasileiro \& Dusi, 1999).

Os tradicionais programas de pesquisa em melhoramento vegetal estão sendo constantemente integrados às novas técnicas biotecnológicas, a fim de solucionar diversos problemas decorrentes do processo usual de seleção (Cohen, 1993). As plantas transgênicas estão sendo incorporadas gradativamente à produção agrícola em diversos países do mundo, sendo que os primeiros plantios em grande escala iniciaram nos Estados Unidos da América, em 1996, com a introdução da soja resistente a herbicidas (Silveira \& Buainain, 2007; CiB, 2021).

No último ano, 26 países foram responsáveis pela produção em escala comercial de diversos alimentos transgênicos, distribuídos em uma área de 191,7 milhões de hectares. No Brasil, de acordo com o recente levantamento do Serviço Internacional para Aquisição de Aplicações de Agrobiotecnologia (ISAAA, 2021), existem 51,3 milhões de hectares com culturas transgênicas, o que representam $27 \%$ de todo o cultivo global destes alimentos. Os organismos geneticamente modificados liberados comercialmente no país restringem-se as culturas do milho, algodão, soja, cana-de-açúcar, feijão e eucalipto (CTNBio, 2021; CiB, 2021).

Outras culturas agrícolas relevantes ao agronegócio também se destacam no cenário de pesquisas com transgênicos no Brasil. A citricultura, por sua vez, importante atividade econômica nacional avança promissoramente na liberação em campo de plantas transgênicas resistentes às principais doenças que afetam e impactam negativamente o agronegócio citrícola. Estima-se que $80 \%$ dos custos de produção de citros no Brasil estejam relacionados ao controle de pragas e doenças (FUNDECITRUS, 2021).

A laranjeira doce (Citrus sinensis L. Osbeck), pertencente à família Rutaceae, é a espécie cítrica de maior importância comercial (Sharma et al., 2004). O Brasil é o maior produtor mundial de laranja doce, com uma área colhida de 589.610 hectares e uma produção de 17,07 milhões de toneladas. O estado de São Paulo representa 77,6\% de toda a produção nacional de laranja, correspondente a 13.256.246 toneladas (Instituto Brasileiro de Geografia e Estatística - IBGE, 2021).

Apesar da excelente adaptação das laranjeiras às condições edafoclimáticas brasileiras, o setor citrícola enfrenta inúmeros problemas fitossanitários, com destaque para as doenças causadas por vírus, bactérias e fungos, responsáveis por grandes perdas econômicas no setor citrícola, que ocorrem principalmente devido à ausência de variedades resistentes a esses patógenos (Machado et al., 2011).

O uso de cultivares resistentes é o método mais eficaz na obtenção de plantas tolerantes a estresses bióticos e abióticos, além de garantia de frutos de melhor qualidade e pomares com maiores produtividades. Desta forma, a transformação genética configura-se como uma importante ferramenta na busca pela proteção das variedades contra diferentes patógenos, uma vez que, os genes de resistência ainda não foram encontrados nos genótipos de plantas cítricas comerciais 
(Brunings \& Gabriel, 2003).

A transformação genética de citros foi inicialmente relatada há mais de duas décadas (Kobayashi \& Uchimaya, 1989; Hidaka et al., 1990; Vardi et al., 1990; Moore et al., 1992). Atualmente, diversos genes de interesse agronômico têm sido eficientemente utilizados na transformação genética de citros visando à resistência derivada de patógenos (Boscariol et al., 2006; Barbosa-Mendes et al., 2009; Cardoso et al., 2010; Mendes al., 2010). Existem genes que estimulam o sistema de defesa das plantas, genes que podem codificar proteínas relacionadas à patogênese, genes que codificam moléculas de origem biótica ou abiótica de respostas de defesa de plantas, genes que codificam peptídeos antimicrobianos e genes do próprio genoma do patógeno (Mourão Filho et al., 2010).

Apesar dos grandes avanços científicos em pacotes biotecnológicos empregados na agricultura, a liberação e a comercialização de plantas transgênicas têm sido dificultadas, principalmente, pela falta de informação a respeito do impacto causado no ambiente e à saúde pública, despertando desconfiança de alguns setores da sociedade (Ribeiro \& Marin, 2012). Nos últimos anos, a biotecnologia agrícola em especial as plantas geneticamente modificadas tem sido objeto de intensos debates no âmbito nacional e internacional, tendo a ciência como intermediadora das controvérsias geradas devido às incertezas políticas, econômicas e sociais que o tema envolve (Blancke, 2015). Nesse cenário, o objetivo deste trabalho foi compreender a aceitação ou rejeição dos consumidores quanto ao potencial uso de frutos de laranjeiras doces geneticamente modificadas para o consumo humano e as perspectivas para a futura liberação da produção a nível comercial.

\section{Metodologia}

A pesquisa de campo foi realizada buscando identificar a opinião pública sobre os processos biotecnológicos aplicados na agricultura e seus possíveis impactos no agronegócio citrícola, com ênfase na problemática do consumo de frutos de laranjeiras doces geneticamente modificadas na alimentação humana.

Por meio de aplicação de questionário online, conduziu-se uma pesquisa com participantes não identificados, elaborado na plataforma do Google ${ }^{\circledR}$ Formulários, contando com a participação voluntária de 318 entrevistados. Foram elaboradas 12 perguntas objetivas e subjetivas, que ficaram disponíveis para o recebimento de respostas entre os dias 15 de julho a 30 de setembro de 2019. As perguntas formuladas basearam-se em levantamentos e trabalhos científicos anteriores aplicados à opinião pública com temas referentes ao consumo de alimentos transgênicos na alimentação humana. Os dados obtidos foram analisados através de estatística descritiva.

O critério de seleção amostral baseou-se na aleatorização dos entrevistados, uma vez que o questionário foi aplicado a diferentes grupos da sociedade, com a cautela de abranger o maior número de pessoas e obter ampla representatividade de consumidores e demais públicos. O questionário online também foi aplicado em eventos técnico-científicos destinados a agricultores, pesquisadores, citricultores, alunos de universidades públicas e privadas, funcionários de empresas e demais participantes. No questionário desconsiderou-se informações relativas ao gênero, faixa etária, classe social e região dos entrevistados, permitindo-se assim, obter a pluralidade da opinião pública sobre o referido assunto.

As questões foram elaboradas procurando mensurar inicialmente o conhecimento dos entrevistados sobre transgenia, interesse, fontes de informação, percepção geral e sua importância no contexto da produção de alimentos. Outras questões abordaram assuntos relacionados à biotecnologia de citros, assim como as pesquisas envolvidas neste tema, os problemas fitossanitários que impactam o agronegócio citrícola, os possíveis benefícios da utilização da transgenia como alternativa de produção e as perspectivas para o consumo e liberação de laranjas transgênicas para a alimentação mundial.

\section{Resultados e Discussão}

Os avanços da biotecnologia na área vegetal têm sido acompanhados por grandes polêmicas e disputas, devido, 
principalmente, às transformações que o desenvolvimento dos programas de melhoramento genético tem acarretado o setor agrícola. A produção de alimentos transgênicos no decorrer das últimas décadas tem centralizado os debates em torno dos avanços das biotecnologias agrícolas e seus impactos sociais, políticos, econômicos e ambientais gerados em todo o mundo, e principalmente no Brasil, país de destaque para o agronegócio.

A partir desta perspectiva, os dados desta pesquisa de opinião pública, podem constituir em um input fundamental para futuros processos de legislação e regulação de inovações científico-tecnológicas, em especial a utilização de frutos de laranjeiras geneticamente modificadas para o consumo humano.

\subsection{Conhecimento, interesse, fontes de informações, segurança e percepção geral sobre a produção de alimentos transgênicos}

Primeiramente, os participantes foram questionados quanto ao grau de conhecimento sobre os alimentos transgênicos, sendo que, 93,4\% dos entrevistados possuem alguma informação a respeito do assunto abordado. Do total dos entrevistados, $63,2 \%$ são a favor do consumo de alimentos geneticamente modificados e 18,2\% são contra (Figura 1). Desta forma, uma das justificativas para a compreensão das atitudes favoráveis ou desfavoráveis do público em relação aos transgênicos, seja em pesquisas qualitativas ou quantitativas, é o nível de informação dos entrevistados, requisito imprescindível para aumentar o poder decisório dos cidadãos (Guivant, 2006).

Figura 1. Aceitação de alimentos transgênicos para o consumo humano, em porcentagem. Representação elaborada a partir das respostas à pergunta: Você é a favor ou contra o uso de alimentos transgênicos?

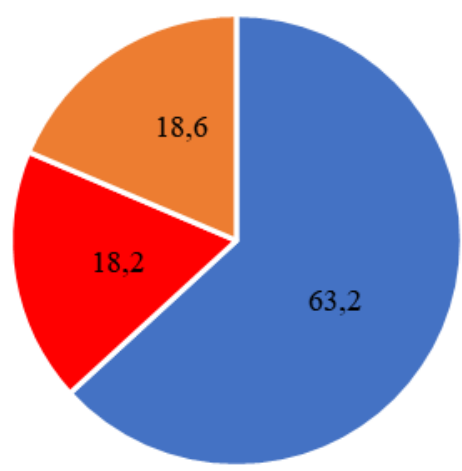

- A FAVOR - CONTRA = NÃO SEI RESPONDER

Fonte: Resultados originais da pesquisa.

Em relação às informações sobre os alimentos transgênicos, 65,7\% dos entrevistados afirmaram que recentemente tiveram acessos aos conteúdos desta natureza. A internet $(49,7 \%)$ e as revistas e textos informativos $(47,5 \%)$ aparecem como os principais veículos de informação (Figura 2). A participação de órgãos públicos e privados de pesquisas como importantes agentes disseminadores de informações também tiveram destaque, representando $41,2 \%$ das opiniões dos entrevistados. 
Figura 2. Fontes de informação sobre os transgênicos. Representação elaborada a partir das respostas à pergunta: Você tem ou teve informações sobre alimentos transgênicos?

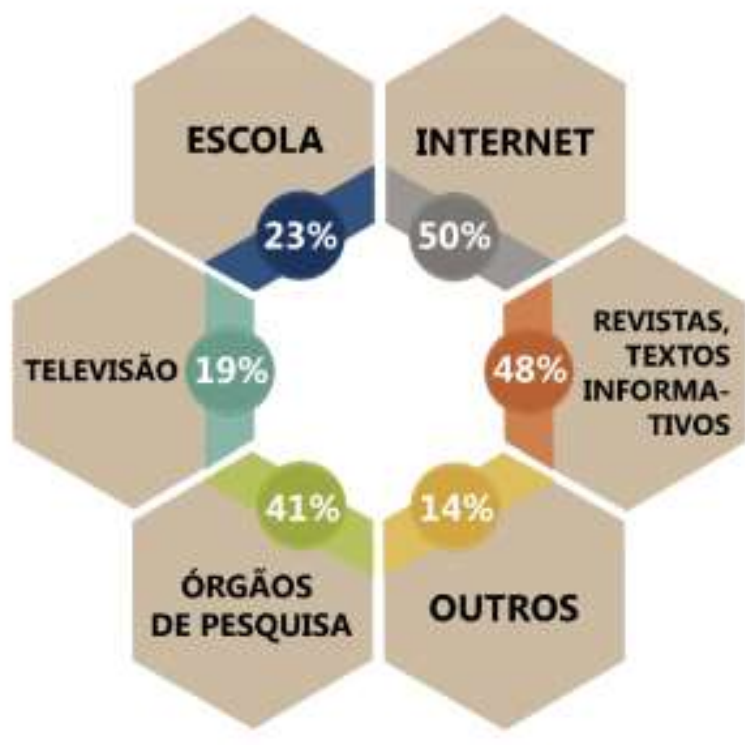

\section{$14 \%$ NÃO ME INFORMO}

Fonte: Resultados originais da pesquisa.

Em relação aos conceitos relativos aos organismos geneticamente modificados e a transgenia, 52,5\% dos participantes acreditam que há diferenças de terminologia entre si, evidenciando um equilíbrio nas respostas.

Segundo a definição do Conselho de Informação de Biotecnologia, transgênicos e Organismos Geneticamente Modificados [OGM] possuem significados distintos. Desta forma, todo organismo que tiver seu DNA modificado é considerado um OGM, independente da origem do material genético. Essa modificação pode ou não inserir um gene externo no DNA do organismo e, quando receber um gene externo, o organismo será um transgênico e um OGM (CiB, 2021). De acordo com Hoban (2004), a diferença de terminologia em pesquisas de opinião pública pode ocasionar oscilações de 10 a $20 \%$ do nível de aceitabilidade sobre os transgênicos, apesar de que muitas vezes as pesquisas tendem a utilizar os conceitos de forma indiferenciada.

Apesar da maioria dos entrevistados responderem que possuem conhecimento sobre os alimentos transgênicos, poucos enumeraram com exatidão as culturas geneticamente modificadas (GM) disponíveis no Brasil à nível comercial. O país cultiva hoje plantas transgênicas de soja, milho, feijão, algodão, cana-de-açúcar e eucalipto (CTNBio, 2021). Na pesquisa, os dois primeiros foram citados por $55 \%$ e $48 \%$ dos entrevistados, respectivamente. A resposta correta foi mencionada por apenas $18 \%$ dos participantes, porém os mesmos acrescentaram outros produtos à lista, como trigo, tomate, alface, abacaxi, maçã, morango, cenoura, mamão que não possuem versões GM no mercado (Figura 3). Muitos entrevistados mencionaram alimentos de consumo humano derivados de soja e milho, como sucos, farinhas, salgadinhos industrializados, óleos, além de outros alimentos de consumo animal, como rações. 
Figura 3. Conhecimento sobre alimentos transgênicos. Representação elaborada a partir das respostas à pergunta: "Você conhece algum alimento transgênico? Cite exemplos”. Nota-se que nem todos os alimentos mencionados são produzidos e liberados para o consumo no país.

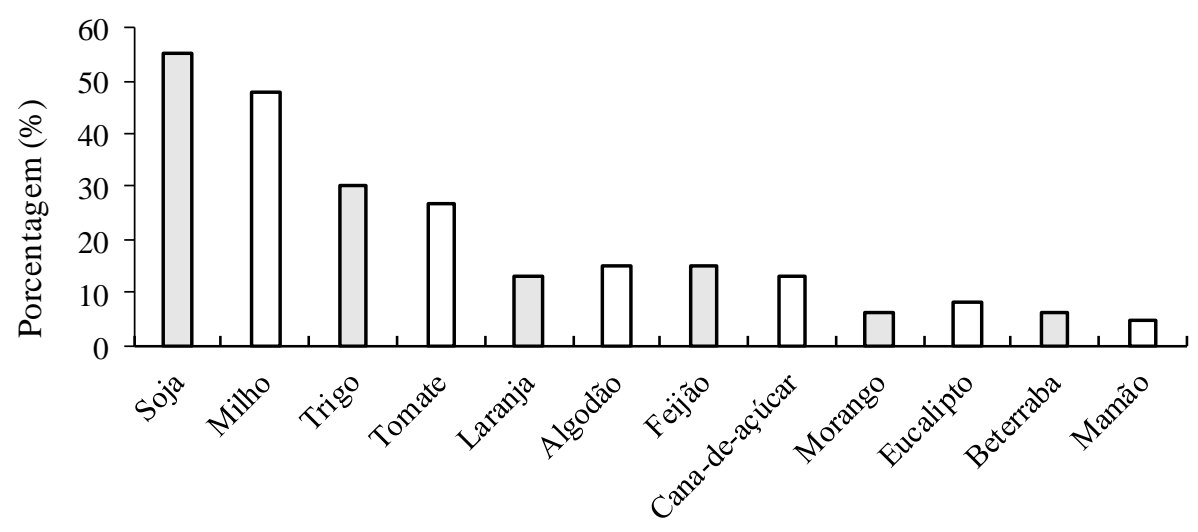

Culturas agrícolas

Fonte: Resultados originais da pesquisa.

Ao serem questionados sobre a segurança dos transgênicos, observa-se que, apesar de estudos científicos, testes e análises de biossegurança demonstrarem claramente que esses alimentos são seguros (König et al., 2004), 18,9\% dos entrevistados afirmaram que os mesmos fazem mal e 38,4\% acharam que possivelmente esses alimentos podem causar algum prejuízo à saúde e ao meio ambiente (Figura 4).

Figura 4. Segurança no consumo de alimentos transgênicos, em porcentagem. Representação elaborada a partir das respostas à pergunta: "Em sua opinião, os transgênicos fazem mal à saúde e/ou ao meio ambiente?"

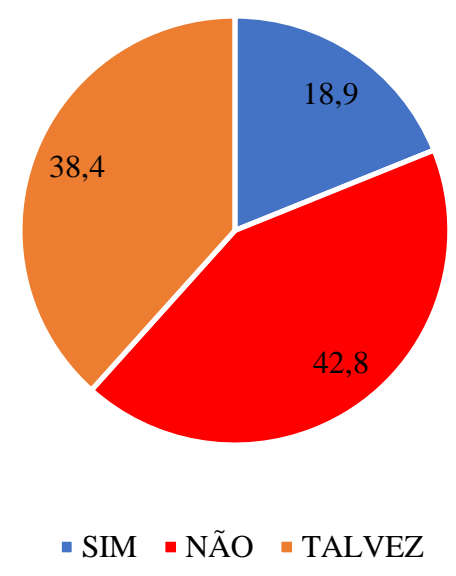

Fonte: Resultados originais da pesquisa.

Ainda que a percepção pelos consumidores não esteja alinhada com os dados científicos, o índice de respondentes que atribui características negativas aos transgênicos está de acordo com o grau de aceitação desses alimentos, na avaliação deste trabalho. A grande maioria $(87,1 \%)$ afirmou já tê-los consumido e 12,9\% não souberam ou afirmaram que não comeram 
(Figura 5).

Figura 5. Consumo de alimentos transgênicos, em porcentagem. Representação elaborada a partir das respostas à pergunta: "Você consome alimentos transgênicos?"

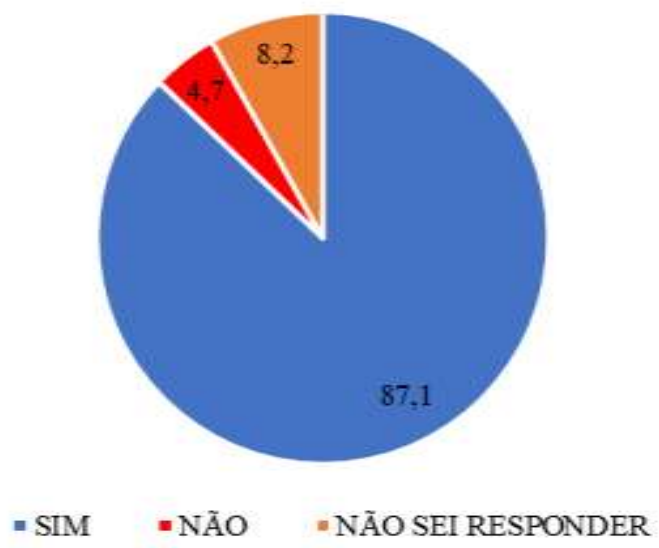

Fonte: Resultados originais da pesquisa.

\subsection{Biotecnologia de citros: pesquisas, utilização destas ferramentas como alternativa de produção e perspectivas de} consumo e liberação

No que concerne aos conhecimentos sobre as pesquisas envolvendo laranjas transgênicas no Brasil, $95 \%$ dos entrevistados desconhecem totalmente quais entidades e/ou órgãos de pesquisas que abordam a biotecnologia de citros como ferramenta para a produção de laranjas transformadas para qualquer finalidade de melhoramento. Atualmente o Instituto Agronômico de Campinas (IAC - Centro de Citricultura 'Sylvio Moreira'), EMBRAPA Mandioca e Fruticultura, Laboratório Nacional de Biociências - CNPEM, Escola Superior de Agricultura 'Luiz de Queiroz' (ESALQ/USP), Instituto Biológico de São Paulo e Fundecitrus desenvolvem pesquisas com plantas transgênicas de citros no Brasil.

Porém, esse resultado contradiz com o conhecimento dos entrevistados sobre o apontamento das principais doenças de laranjeiras. O Huanglongbing ou greening foi a doença mais mencionada entre os entrevistados, com 53\%, seguidos de cancro cítrico (18\%), pinta preta (12\%), leprose dos citros $(6 \%)$, além de outras doenças apontadas como a ferrugem, verrugose, morte súbita dos citros. Somente $28 \%$ dos entrevistados não conheciam nenhuma doença dos citros.

As principais doenças bacterianas presentes nos cultivos comerciais são o cancro cítrico causado por Xanthomonas citri subsp. citri (Schaad et al., 2006) e o huanglongbing (HLB ou Greening) que estão associados a três espécies endêmicas de Candidatus Liberibacter spp. (Colleta Filho et al., 2004; Halbert, 2005; Teixeira et al., 2005). Contudo, a transformação genética de citros configura-se como uma importante ferramenta como alternativa em busca de genes de resistência aos principais patógenos causadores de doenças.

Apesar da maioria dos entrevistados ter conhecimento sobre as principais doenças das laranjeiras, 56\% dos participantes acreditaram que a transgenia conseguiria controlar parcialmente os problemas fitossanitários desta cultura (Figura 6). Esse resultado revelou que o consumidor ainda não relaciona a produção de alimentos com a aplicação de conhecimento científico, ou acreditam que essas doenças são muito agressivas e não veem esta ferramenta como opção de controle fitossanitário no manejo agrícola. 
Figura 6. Transgenia como alternativa para o controle de pragas e doenças dos citros, em porcentagem. Representação elaborada a partir das respostas à pergunta: "Você acreditaria que a transgenia poderia resolver os problemas fitossanitários das laranjeiras?"

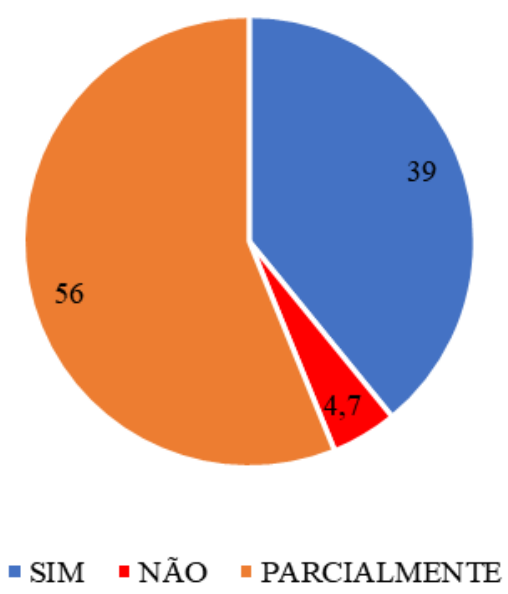

Fonte: Resultados originais da pesquisa.

Na questão relacionada à possível liberação da produção comercial de laranjeiras transgênicas, 66,4\% dos entrevistados consumiriam o fruto in natura ou suco de laranja transgênica. Uma parcela da população respondeu que consumiria moderadamente $(14,5 \%)$ ou somente algumas vezes $(9,1 \%)$ e $10,1 \%$ não consumiriam laranjas transgênicas em hipótese alguma (Figura 7).

Figura 7. Consumo de produtos transgênicos de citros, em porcentagem. Representação elaborada a partir das respostas à pergunta: "Caso as laranjeiras transgênicas fossem liberadas pela CTNBio para produção comercial, você consumiria o fruto in natura ou suco de laranja transgênica?"

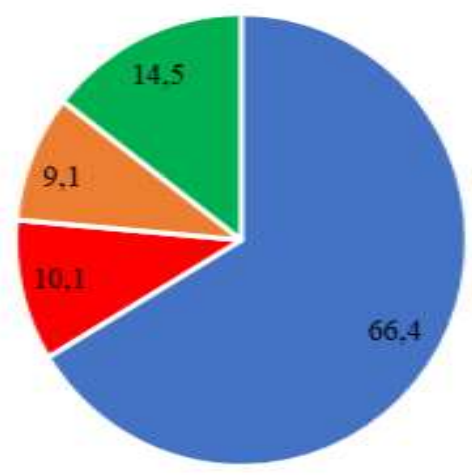

" SIM "NÃO "ALGUMAS VEZES "MODERADAMENTE

Fonte: Resultados originais da pesquisa.

Apesar da grande aceitação, a transgenia despertou desconfiança de alguns setores da sociedade desde a sua introdução no país. A expectativa diante de uma nova ferramenta para facilitar a produção de alimentos ganhou contornos 
ideológicos e as dúvidas se transformaram em posicionamentos críticos a respeito dos transgênicos (Blancke, 2015). Desta forma, as pesquisas de opinião pública tornaram relevantes, passando a ser utilizadas para caracterizar o sentimento dos consumidores e respaldar políticas rigorosas.

A maioria das respostas obtidas sobre as perspectivas para o consumo das laranjas transgênicas na alimentação mundial apontou a falta de informação sobre os possíveis danos à saúde e ao ambiente como principal entrave para a aprovação. Além disso, o termo 'transgênico' é um marketing negativo associado à citricultura, tornando-se um grande obstáculo para a inserção destes produtos na alimentação.

Desta forma, muitas respostas tiveram um viés negativo para a aceitação no mercado, apontando muitos mitos e tabus em relação às plantas transgênicas, o que leva à resistência da população ao consumo. Outras respostas alegaram que as restrições serão altas, principalmente em relação à entrada desses produtos no mercado europeu, o que dificultaria todo o processo de regulamentação.

Muitas respostas foram favoráveis e positivas em relação às perspectivas para o consumo e produção de frutos de laranjas transgênicas. A principal justificativa para a liberação desses alimentos está associada ao aumento da população mundial, necessitando de tecnologias, como a da transgenia, para suprir a demanda por alimentos, visando sempre uma produção sustentável. A introdução de genes em plantas transgênicas visando a resistência a diversos patógenos, como o HLB, principal doença da citricultura, foi relatada em muitas das respostas como mecanismo fundamental para o controle ou tolerância a esta doença, o que permitiria a manutenção de pomares comerciais com alta produtividade.

Ainda que tenha havido avanços ao longo do tempo no entendimento sobre o conceito de transgenia, esta pesquisa revelou que ainda há vários equívocos conceituais e de aplicação em relação a biotecnologia na produção de alimentos. Fatores psicológicos, culturais e econômicos podem levar os consumidores a desenvolverem convicções divergentes da ciência e com elevado viés ideológico, como é o caso dos transgênicos (Lusk et al., 2014).

\section{Conclusão}

Há uma preocupação aparente dos consumidores com a segurança ambiental e nutricional de alimentos transgênicos para o consumo humano, em especial aos frutos de laranjeiras geneticamente modificadas. Apesar disso, observou-se através de pesquisa de opinião pública que há alta aceitação no consumo de laranjas transgênicas, caso fossem liberadas para comercialização. Há alta perspectiva da população para que a transgenia se torne uma importante alternativa no controle das principais doenças dos citros.

\section{Agradecimentos}

Ao Programa de Educação Continuada em Economia e Gestão de Empresas (PECEGE) pelo oferecimento de bolsa de estudos para cursar o MBA em Agronegócios da Escola Superior de Agricultura 'Luiz de Queiroz'/Universidade de São Paulo.

\section{Referências}

Barbosa-mendes, J. M., Mourão Filho, F. A. A., Bergamin Filho, A., Harakava, R., Beer, S. V., Mendes, B. M. J. (2009). Genetic transformation of Citrus sinensis cv. 'Hamlin' with hrpN gene from Erwinia amylovora and evaluation of the transgenic lines for resistance to citrus canker. Scientia Horticulturae, Amsterdam, (122), 109-115.

Blancke, S. \& Breusegem, F. V. (2015). Fatal attraction: the intuitive appeal of GMO opposition. Trends in Plant Science, 20(7), 414-418.

Boscariol, R. L., Monteiro, M., Takashi, E. K., Charbregas, S. M., Vieira, M. L. C., Vieira, L. G. E, Pereira, L. F. P., Mourão Filho, F. A. A., Cardoso, S. C., Christiano, R. S. C., Bergamin Filho, A, Barbosa, J. M., Azevedo, F. A., Mendes, B. M. J. (2006). Attacin A gene from Tricloplusia ni reduces susceptibility to Xanthomonas axonopodis pv. citri in transgenic Citrus sinensis 'Hamlin'. Journal of the American Society for Horticultural Science, 131(4), 530-536.

Brasileiro, A. C. M. \& Dusi, D. M. A. (1999). Transformação genética de plantas. In: Torres, A. C., Caldas, L. S., Buso, J. A. Cultura de tecidos e transformação genética de plantas. Brasília: EMBRAPA, (2), 679-736. 
Brunings, A. M. \& Gabriel, D. W. (2003). Xanthomonas citri: breaking the surface. Molecular Plant Pathology, (4), $141-157$.

Cardoso, S. C, Barbosa-Mendes, J. M, Boscariol Camargo, R. L, Christiano, R. S., Bergamin Filho, A, Vieira, M. L. C, Mendes, B. M. J, Mourão Filho, F. A. A. (2010). Transgenic sweet orange (Citrus sinensis L. Osbeck) expressing the attacin A gene for resistance to Xanthomonas citri subsp. citri. Plant Molecular Biology Reporter, (28), 185-192.

Cohen, J.I. (1993). An intemational initiative in biotechnology: priorities, values and implementation of an AID project. Crop Science, (33), 913-918.

Coletta-Filho, H. D., Takita, M. L. P., Carlos, E. F., Machado, M. A. (2004). A bacteria 'Candidatus Liberibacter' em plantas com huanglongbing (exgreening) no Estado de São Paulo. Laranja, Cordeirópolis, (25), 367-374.

Comissão Técnica Nacional de Biossegurança [CTNBio]. s.d. < http://ctnbio.mctic.gov.br/liberacao-comercial\#/liberacao-comercial/consultar-processo>. Acesso em: 10 set. 2021.

Conselho de Informações Sobre Biotecnologia [CIB]. s.d. <https://cibpt.org/produtos-aprovados/>.

Diouf, D. (2003). Genetic transformation of forest trees. African Journal Biotechnology, 2(10), 328-333.

FUNDECITRUS. <unidoscontraogreening.com.br>.

Guivant, J. S. (2006). Transgênicos e percepção pública da ciência no Brasil. Ambient. society, 9(1), 81-103.

Halbert, S. E. \& Manjunath, K. L. (2004). Asian citrus psyllid (Sternorrhyncha: Psyllidae) and greening disease of citrus: a literatura review and assessment of risk in Florida. Florida Entomologist, (87), 330-353.

Hidaka, T., Omura, M., Ugaki, M., Tomiyama, M., Kato, A., Ohshima, M., Motoyoshi, F. (1990). Agrobacterium-mediated transformation and regeneration of Citrus spp. from suspension cells. Japanese Journal of Breeding, (40), 199-207.

Hoban, T. (2004). Public attitudes towards agricultural biotechnology. ESA Working Paper N. 04-09.

Instituto Brasileiro de Geografia E Estatística [IBGE]. Levantamento Sistemático da produção agrícola. 〈http://www.sidra.ibge.gov.br/bda/agric>.

Kobayashi, S. \& Uchimiya, H. (1989). Expression and integration of a foreign gene in orange (Citrus sinensis L. Osbeck) protoplast by direct DNA transfer. Japanese Journal of Genetics, (64), 91-97.

Konig, A, Cockburn, A, Crevel, R. W. R, \& Debruyne, E. (2004). Assessment of the safety of foods derived from genetically modified (GM) crops. Food and Chemical Toxicology, (42),1047-1088.

Lusk, J.L., Roosen, J, \& Bieberstein, A. (2014). Consumer acceptance of new food technologies causes and roots controversies. Annu Rev Resour Econ, (6), $381-405$.

Machado, M. A., Cristofani-Yaly, M., \& Bastianel, M. (2011). Breeding, genetic and genomic of citrus for disease resistance. Revista Brasileira de Fruticultura, Jaboticabal, 33(1), 34-45.

Mendes, B. M. J., Cardoso, S. C., Boscariol-Camargo, R. L., Cruz, R. B., Mourão Filho, F. A. A., \& Bergamin Filho, A. (2010). Reduction in susceptibility to Xanthomonas axonopodis pv. citri in transgenic Citrus sinensis expressing the rice Xa21 gene. Plant Pathology, (59), 68-75.

Moore, G. A., Jacano, C. C., \& Neidigh, J. L. (1992). Agrobacterium-mediated transformation of citrus stem segments and regeneration of transgenic plants. Plant Cell Reports, (11), 238-242.

Mourão Filho, F. A. A., Stipp, L. C. L., \& Mendes, B. M. J. (2010). Perspectivas da produção e utilização de transgênicos para o controle do huanglongbing. Citrus Research \& Technology, 31(1), 91-100.

Ribeiro, I. G \& Marin, V. A. (2012). A falta de informação sobre os Organismos Geneticamente Modificados no Brasil. The lack of information on Genetically Modified Organisms in Brazil.

Schaad, N. W., Postnikova, E., Lacy, G., Sechler, A., Agarkova, I.V., Stromberg, P. E., \& Vidaver, A. M. (2006). Emended classification of Xanthomonas pathogens on citrus. Plant Pathology, (29), 690-695.

Sharma, B. D. Hore, D. K., \& Gupta, S. G. (2004). Genetic resources of Citrus of north-eastern India and their potential use. Genetic Resources and Crop Evolution, (51), 411-418.

Silveira, J. M. \& Buainan, A. M. (2007). Aceitar riscos controlados para inovar e vencer desafios. In: VEIGA, J. E. (Org.). Transgênicos: sementes da discórdia. SENAC.

Teixeira, D. C, Danet, J. L, Eveillard, S, Martins, E. C, Jesus Junior, W. C, Yamamoto, P. T, Lopes, A. S, Bassanezi, R. B, Ayres, A. J, Saillard, C, \& Bové, J. M. (2005). Citrus huanglongbing in São Paulo State, Brazil: PCR detection of the 'Candidatus' Liberibacter species associated with the disease. Molecular and Cellular Probes, (19), 173-179.

Vardi, A, Blechman, K, \& Aviv, D. (1990). Genetic transformation of Citrus protoplasts and regeneration of transgenic plants. Plant Science, 69(2), 199-206. 